\title{
Comparison of Human Chorionic Gonadotropin Test and Amnisure Test for Diagnosis of Premature Rapture of Membrane
}

Esmat Barooti (MD)

Department of Obstetrics \&

Gynecology, Taleghani Hospital,

Shahid Beheshti University of Medical

Sciences, Tehran, Iran

Soodabeh Darvish (MD)

Department of Obstetrics \&

Gynecology, Taleghani Hospital,

Shahid Beheshti University of Medical

Sciences, Tehran, Iran

Nourossadat Kariman (MSc)

Faculty of Nursing and Midwifery,

Shahid Beheshti University of Medical

Sciences, Tehran, Iran

Ghasem Yazdanpanah (MD)

Students' Research Committee, Shahid

Beheshti University of Medical

Sciences, Tehran, Iran

Corresponding author: Soodabeh

Darvish

Address: Taleghani Hospital, Yaman St, Shahid Chamran Highway, Tehran, Iran

Tel:+98-2122432570

Email: darvishsudabeh@sbmu.ac.ir

Address: Taleghani Hospital, Shahid Beheshti University of Medical Sciences, Tehran, Iran

Received: 05 May 2018

Revised: 05 Sep 2018

Accepted: 25 Sep 2018
ABSTRACT

Background and objectives: Accurate diagnosis of preterm rupture of membrane (PR0M) is critical during pregnancy, and researchers are seeking ways to decrease the rate of false negative results in diagnostic tests. In the present study, we compare diagnostic properties of Amnisure test and human chorionic gonadotropin (hCG) test for diagnosis of PR0M.

Methods: The study was performed on singleton pregnant women (gestational age: 20 to 41 weeks) who were referred to the Taleghani Hospital in Tehran (Iran) between December 2016 and December 2017. The study included 44 PROM patients and 44 control pregnant women. Speculum examination for cervicovaginal fluid washing, hCG test and Amnisure test were performed for all of patients. Statistical analysis of data was performed in SPSS software package (Version 18, Chicago, IL, ISA) using t-test, Chi-square test, and Mann-Whitney test. P-values less than 0.05 were considered statistically significant.

Results: The Amnisure test had better sensitivity and specificity compared with the $\beta$-hCG test $(95.5 \%$ and $97.7 \%$ vs. $93.2 \%$ and $95.5 \%)$. The Amnisure test also had higher positive and negative predictive values than the $\beta$-hCG test $(97.7 \%$ and $95.5 \%$ vs. $93.3 \%$ and 94.3\%). Diagnostic accuracy of the Amnisure test was also higher than that of the $\beta$-hCG test (96.6\% vs. $94.3 \%)$.

Conclusion: According to the results, the two tests have almost equal diagnostic power for detection of PR0M during pregnancy.

Keywords: Chorionic Gonadotropin, Fetal Membranes, Premature Rupture.

This paper should be cited as: Barooti E, Darvish S, Kariman N, Yazdanpanah GH [Comparison of Human Chorionic Gonadotropin Test and Amnisure Test for Diagnosis of Premature Rapture of Membrane]. mljgoums. 2019; 13(1):28-32 


\section{INTRODUCTION}

Premature rapture of membrane (PROM) occurs in more than $20 \%$ of all pregnancies at either term or preterm labor. However, it is confirmed only in nearly half of suspected pregnant women (1). Optimal management of PROM relies on the timely identification of early presentations during pregnancy. In management of PROM, depending on its severity, a gynecologist might decide to prescribe antibiotics and corticosteroid or even terminate the pregnancy $(2,3)$. In clinical settings, history of PROM alone is not sufficient and there is a $12 \%$ false negative error rate in clinical examination of suspected cases (4). Some mistakes in clinical diagnosis of PROM can lead to inappropriate interventions, such as hospitalization and labor induction. According to some studies, history taking is reliable only in $10-50 \%$ of patients and inspection of cervical fluid leakage has a $12-30 \%$ false negative error rate $(5,6)$. To cover the noted gap for PROM diagnosis in pregnant women, methods such as assessment of vaginal $\mathrm{pH}$ with nitrazine sticks, presence of ferning in vaginal fluid, and amniotic fluid volume have been suggested. Although the aforementioned tests might be beneficial for PROM diagnosis to some extent, most of them are inaccurate (7-9). The indigo carmine injection is considered as the gold standard diagnostic method, but is extremely invasive and not suitable for routine practice (10). The traditional gold standard diagnosis for PROM was related to three clinical signs during speculum examination: visual pooling of clear fluid in the posterior fornix of the vagina or fluid leakage from the cervical os, alkaline $\mathrm{pH}$ of the cervicovaginal discharge, and microscopic ferning of the cervicovaginal discharge upon drying (11). These tests also produced high rate of false positive or negative results (12). Different biomarkers such as fetal fibronectin (13), alpha fetoprotein (14), insulin-like growth factor binding protein-1 ( 9 , 14), placental alpha-microglobuline-1 (15), and beta-subunit of human chorionic gonadotropin ( $\beta$-hCG) (6) have been used to produce accurate diagnostic tools for PROM. Generally, $\beta$-hCG is present in varying concentrations $(2000-70,000 \mathrm{mIU} / \mathrm{mL})$ in serum, urine, and amniotic fluid during pregnancy. It might be also present in vaginal fluid since it is secreted by the cervical glands. Hence, measuring $\beta$-Hcg could be beneficial for the diagnosis of PROM (16). Temel et al. suggested determination of $\beta$-hCG level in vaginal washing fluid as a proper and simple method of detecting fluid leakage from vagina. Esim et al. also claimed that measuring $\beta$-hCG level in vaginal washing fluid is a rapid, reliable and simple test for the diagnosis of PROM (6). Moreover, a study by Kariman et al. revealed that the cervicovaginal hCG measurement by ELISA has $90 \%$ sensitivity, 92\% specificity, $92.1 \%$ positive predictive value (PPV), 90\% negative predictive value (NPV), and 91\% accuracy. Recently, some studies have proposed detection of some biomarkers in the amniotic fluid instead of vaginal fluid. Amnisure is a test for measuring placental alpha microglobuline-1 (PAMG-1) in amniotic fluid of PROM-suspected pregnant women $(17,18)$. PAMG-1 level is $1,000-$ to 10,000 -fold higher in amniotic fluid than in cervicovaginal secretions (17). According to some studies, the Amnisure test has high sensitivity and specificity for the diagnosis of PROM (17-19). However, it is more expensive and less accessible than other methods. Therefore, we conducted this study to compare diagnostic power of the Amnisure test and rapid hCG test for diagnosis of PROM during pregnancy.

\section{MATERIALS AND METHODS}

Study population included pregnant women referred to the prenatal clinic and embryology department of Taleghani Hospital in Tehran (Iran) between December 2016 and December 2017. The subjects were enrolled via convenience sampling and then divided into a case group $(\mathrm{N}=44)$ and a control group $(\mathrm{N}=44)$. The formula below was used to calculate the sample size:

$\mathrm{n}=\llbracket\left(\mathrm{z}_{-}(1-\propto / 2)\right) \rrbracket \wedge 2 \times \mathrm{p}(1-\mathrm{p}) / \mathrm{d}^{\wedge} 2$

$\alpha=0.05, Z_{1-\alpha / 2}=1.96$

The case group included singleton pregnant women with gestational age of 20-41 weeks and a history of ROM at or after 24 weeks of gestation but not in labor, which presented with fluid discharge as the chief complaint in prenatal visit. The control group included agematched healthy pregnant women. Study protocol received approval from the research ethics committee of Shahid Beheshti University of Medical Sciences, and written consent was taken from all participants. 
Women with fetal anomalies, intrauterine fetal death, known diseases, pregnancy complications, visible blood in vaginal secretions, meconium in amniotic fluid, and uterine contractions as well as those with a history of taking vaginal drugs or intercourse in the prior night were excluded from the study.

Gestational age of pregnant women was determined based on the first day of the last menstrual period or by sonographic assessment at gestational age of less than 14 weeks or two sonographic assessments at gestational age of 14 to 24 weeks. The subjects were examined in lithotomy position and leakage of fluid was inspected using a sterile speculum. Results were reported as positive, negative, or suspicious. A cotton-tipped applicator was inserted in vagina and then immediately transferred onto nitrazine paper. The samples with $\mathrm{pH}$ of $>6.5$ were considered positive. A sample was also taken from cervicovaginal secretions in a similar manner. The samples were studied under a light microscope (10X magnification) to detect ferning pattern. In addition to demographic data (age, education, job, gestational age, gravid, parity), the results of speculum examination, the fern and nitrazine test (Macherey-Nagel GmbH \& Co., Germany), the hCG test (dipsticks with cut-off value of 25 $\mathrm{mIU} / \mathrm{mL}$ purchased from ACON Inc., USA) and the Amnisure test (International LLC, USA) were recorded.

Control solutions were used for confirming the validity of the hCG and the Amnisure tests.
Two cotton-tipped applicators were inserted into the posterior fornix and samples were transferred to two separate tubes; one filled with $3 \mathrm{~mL}$ of normal saline and another with Amnisure solvent. Then, hCG dipstick was immersed in $3 \mathrm{~mL}$ of normal saline up to the marked line for ten to fifteen seconds, while the Amnisure dipstick was immersed in a special lotion. Result of each test was read after ten minutes. PROM was confirmed in patients with positive pooling, nitrazine and fern test results, while pregnant women with negative pooling, nitrazine and fern test results were considered as the control group.

Statistical analysis of data was performed in SPSS software package (Version 18, Chicago, IL, USA) using t-test, Chi-square test, and Mann-Whitney test. P-values less than 0.05 were considered statistically significant.

\section{RESULTS}

The demographic characteristics did not differ significantly between the two study groups (Table 1).

In the case group, 42 cases had true positive and 2 cases had false negative results in the hCG ACON dipstick test. Conversely, in the control group, 2 false positive and 42 true negative cases were reported in the hCG ACON dipstick test. In the Amnisure test, 42 were true positive and 2 were false negative in the case group, while 43 were true negative and one was false positive in the control group. Overall, the Amnisure test had better diagnostic properties compared with the $\beta$ hCG test (Table 2).

Table1- Demographic characteristics of pregnant women with PROM and healthy pregnant women

\begin{tabular}{cccc}
\hline Variable & Case group & Control group & P-value \\
\hline Age (Mean \pm SD) & $28.93 \pm 5.69$ years & $27.91 \pm 4.05$ years & $0.35^{*}$ \\
Education (High school diploma) & $63.6 \%$ & $61.4 \%$ & $0.27^{* *}$ \\
Job (homemaker) & $45.5 \%$ & $\mathbf{5 0 \%}$ & $0.95^{* *}$ \\
Gestational age (Mean \pm SD) & $36.09 \pm 1.22$ weeks & $36.21 \pm 1.02$ weeks & $0.55^{*}$ \\
Gravidity (Mean \pm SD) & $1.82 \pm 0.97$ & $1.95 \pm 0.78$ & $0.25^{*}$ \\
Parity (Mean \pm SD) & $0.92 \pm 0.75$ & $0.84 \pm 0.74$ & $0.32 *$ \\
\hline
\end{tabular}

\footnotetext{
* Student T-test
}

** Chi square $\left(\mathbf{X}^{2}\right)$ test

Table 2- Diagnostic properties of the $\beta$-hCG test and Amnisure for diagnosis of PROM during pregnancy

\begin{tabular}{cccccc}
\hline Test & Sensitivity & Specificity & PPV & NPV & Accuracy \\
\hline B-hCG test (ACON) & $\mathbf{9 3 . 2 \%}$ & $\mathbf{9 5 . 5 \%}$ & $\mathbf{9 5 . 3 \%}$ & $\mathbf{9 3 . 3 \%}$ & $\mathbf{9 4 . 3 \%}$ \\
Amnisure & $\mathbf{9 5 . 5 \%}$ & $\mathbf{9 7 . 7 \%}$ & $\mathbf{9 7 . 7 \%}$ & $\mathbf{9 5 . 5 \%}$ & $\mathbf{9 6 . 6 \%}$ \\
\hline
\end{tabular}


In the receiver operating characteristic (ROC) curve analysis of the two tests, the area under the curve was 0.943 (95\% CI=0.887-0.999,
$\mathrm{P}<0.001)$ for the $\beta$-hCG test and $0.966(95 \%$ $\mathrm{CI}=0.00-0.900, \mathrm{P}<0.001)$ for the Amnisure test (Figure 1).

Figure 1- The ROC curve for the Amnisure and the $\beta$-hCG tests

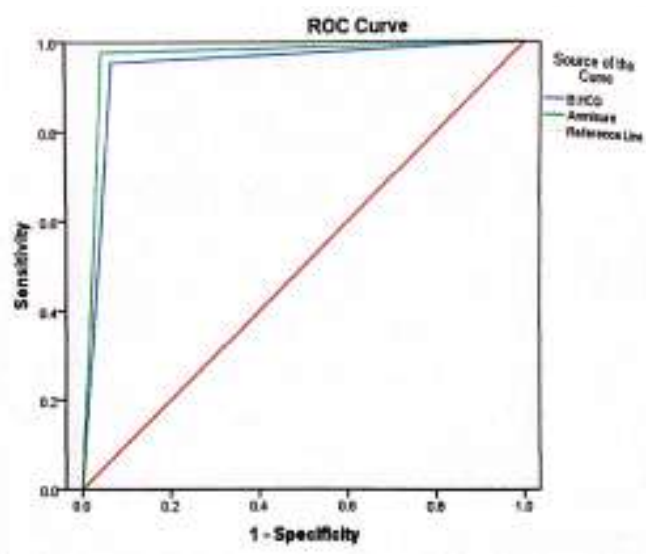

\section{DISCUSSION}

PROM is one of the main causes of perinatal morbidity and mortality among pregnant women $(20,21)$. Currently, there is no gold standard method for diagnosing PROM during pregnancy. In this study, we compared diagnostic characteristics of the Amnisure test and the $\beta$-hCG test for detection of PROM. In the present study, the sensitivity and specificity of the $\beta$-hCG test was $93.2 \%$ and $95.5 \%$ respectively. In addition, the diagnostic accuracy, PPV and NPV of this test were $94.3 \%, 95.35 \%$ and $93.3 \%$, respectively. Renzo et al. reported the sensitivity, specificity, PPV and NPV of the $\beta$-HCG test to be $68-95 \%, 70-95 \%, 73-91 \%$ and $78-97 \%$, respectively (22). In a study by Tian et al., the $\beta$-hCG test had $77.5 \%$ sensitivity, $78.6 \%$ specificity, $80.1 \%$ PPV, and 79.3\% NPV (23). In both mentioned studies, the $\beta$-hCG test had lower specificity and sensitivity compared with our study.

In our study, the sensitivity and specificity of the Amnisure test was 93.2\% and 95.5\%, respectively. Moreover, the PPV, NPV and diagnostic accuracy values of this test were $97.7 \%, 95.5 \%$ and $94.3 \%$, respectively. Our results are similar to the findings of previous studies $(15,22)$.

Overall, the Amnisure test had better diagnostic properties than the $\beta$-hCG test, which is in line with results of a previous study (22). The Amnisure test assesses the presence of high concentrations of glycoprotein PAMG-1 in the cervicovaginal secretion. Concentration of PAMG-1 is high in amniotic fluid, low in blood, and very low in cervicovaginal discharge. This biomarker could be a suitable and accepted diagnostic tool for PROM among suspected pregnant women. The present study showed that the diagnostic characteristic of the Amnisure test are comparable with that of the hCG test. The Amnisure test does not require speculum insertion, which can be pointed out as another advantage of the test for diagnosis of PROM in pregnant women. Cousins et al. also revealed that the Amnisure test is superior to other conventional tests for the correct diagnosis of ROM (17).

In this study, the tests were not performed in replicates, and we did not compare the accuracy of the tests when used together and alone. The direct injection of indigo carmine into the amniotic sac is the gold standard for PROM diagnosis, but we assumed the technique to be too invasive for use in routine practice or research purposes. Therefore, we used a non-invasive clinical technique (hCG test) for diagnosing PROM.

\section{CONCLUSION}

The results implicate that the Amnisure test is a non-invasive and accurate method for diagnosing PROM among suspected pregnant women. The test has relatively better diagnostic properties compared with the $\beta$ hCG test. Nevertheless, high cost of the Amnisure test remains its only limitation. 


\section{ACKNOWLEDGEMENTS}

The authors would like to thank the Shahid Beheshti University of Medical Sciences for supporting this research project.

\section{REFERENCES}

1. Gunn GC, Mishell DR Jr, Morton DG. Premature rupture of the fetal membranes. A review. Am J Obstet Gynecol. 1970; 106(3): 469-83.

2. Kenyon SL, Taylor DJ, Tarnow-Mordi W, Group OC. Broad-spectrum antibiotics for preterm, prelabour rupture of fetal membranes: the ORACLE I randomised trial. ORACLE Collaborative Group. Lancet. 2001; 357(9261): 979-88.

3. Roberts D, Dalziel S. Antenatal corticosteroids for accelerating fetal lung maturation for women at risk of preterm birth. Cochrane Database Syst Rev. 2006(3):CD004454.

4. Ladfors L, Mattsson LA, Eriksson M, Fall O. Is a speculum examination sufficient for excluding the diagnosis of ruptured fetal membranes? Acta Obstet Gynecol Scand. 1997; 76(8): 739-42.

5. Kim YH, Park YW, Kwon HS, Kwon JY, Kim BJ. Vaginal fluid beta-human chorionic gonadotropin level in the diagnosis of premature rupture of membranes. Acta Obstet Gynecol Scand. 2005; 84(8): 802-5.

6. Esim E, Turan C, Unal O, Dansuk R, Cengizglu B. Diagnosis of premature rupture of membranes by identification of beta-HCG in vaginal washing fluid. Eur J Obstet Gynecol Reprod Biol. 2003; 107(1): 37-40.

7. Gorodeski IG, Haimovitz L, Bahari CM. Reevaluation of the $\mathrm{pH}$, ferning and nile blue sulphate staining methods in pregnant women with premature rupture of the fetal membranes. J Perinat Med. 1982; 10(6): 286-92.

8. de Haan HH, Offermans PM, Smits F, Schouten HJ, Peeters LL. Value of the fern test to confirm or reject the diagnosis of ruptured membranes is modest in nonlaboring women presenting with nonspecific vaginal fluid loss. Am J Perinatol. 1994; 11(1): 46-50.

9. Erdemoglu E, Mungan T. Significance of detecting insulin-like growth factor binding protein-1 in cervicovaginal secretions: comparison with nitrazine test and amniotic fluid volume assessment. Acta Obstet Gynecol Scand. 2004; 83(7): 622-6. DOI:10.1111/j.00016349.2004.00343.x

10. Sosa CG, Herrera E, Restrepo JC, Strauss A, Alonso J. Comparison of placental alpha microglobulin-1 in vaginal fluid with intra-amniotic injection of indigo carmine for the diagnosis of rupture of membranes. $\mathbf{J}$ Perinat Med. 2014; 42(5): 611-6. doi: 10.1515/jpm-20130245.

11. ACOG Committee on Practice Bulletins-Obstetrics. ACOG Practice Bulletin No. 80: premature rupture of membranes. Clinical management guidelines for obstetrician-gynecologists. Obstet Gynecol. 2007; 109(4): 1007-19.

12. Friedman ML, McElin TW. Diagnosis of ruptured fetal membranes. Clinical study and review of the literature. Am J Obstet Gynecol. 1969;104(4):544-50.

13. Petrunin DD, Griaznova IM, Petrunina Iu A, Tatarinov Iu S. Immunochemical identification of organ specific human placental alphal-globulin and its concentration in amniotic fluid. Akush Ginekol (Mosk). 1977; (1): 62-4.

\section{CONFLICT OF INTEREST}

The authors declare that there is no conflict of interest.

14. Jeurgens-Borst AJ, Bekkers RL, Sporken JM, van den Berg PP. Use of insulin like growth factor binding protein-1 in the diagnosis of ruptured fetal membranes. Eur J Obstet Gynecol Reprod Biol. 2002; 102(1): 11-4.

15. Khooshideh M, Radi V, Hosseini R, Hosseini L. The accuracy of placental alpha-microglobuline-1 test in diagnosis of premature rupture of the membranes. Iran $\mathrm{J}$ Reprod Med. 2015; 13(6): 355-60.

16. Temel O, Cogendez E, Selcuk S, Asoglu MR, Kaya E. beta-human chorionic gonadotropin assay in vaginal washing fluid for the accurate diagnosis of premature rupture of membranes during late pregnancy. J Turk Ger Gynecol Assoc. 2013; 14(4): 201-4. doi:10.5152/jtgga.2013.65624.

17. Cousins LM, Smok DP, Lovett SM, Poeltler DM. AmniSure placental alpha microglobulin-1 rapid immunoassay versus standard diagnostic methods for detection of rupture of membranes. Am J Perinatol. 2005;22(6):317-20. DOI:10.1055/s-2005-870896.

18. Lee SE, Park JS, Norwitz ER, Kim KW, Park HS, Jun JK. Measurement of placental alpha-microglobulin-1 in cervicovaginal discharge to diagnose rupture of membranes. Obstet Gynecol. 2007;109(3):634-40. DOI:10.1097/01.AOG.0000252706.46734.0a.

19. Martinez MW, Singh CP, Mookadam F. Transcatheter closure of a postinfarction ventricular septal rupture. J Am Soc Echocardiogr. 2006; 19(11): 1401 e5-7.

20. Mercer BM, Goldenberg RL, Meis PJ, Moawad AH, Shellhaas C, Das A, et al. The Preterm Prediction Study: prediction of preterm premature rupture of membranes through clinical findings and ancillary testing. The National Institute of Child Health and Human Development Maternal-Fetal Medicine Units Network. Am J Obstet Gynecol. 2000; 183(3): 738-45.

21. Ananth CV, Oyelese Y, Srinivas N, Yeo L, Vintzileos AM. Preterm premature rupture of membranes, intrauterine infection, and oligohydramnios: risk factors for placental abruption. Obstet Gynecol. 2004; $\quad$ 104(1): 71-7. DOI:10.1097/01.AOG.0000128172.71408.a0.

22. Di Renzo GC, Roura LC, Facchinetti F, Antsaklis A, Breborowicz G, Gratacos E, et al. Guidelines for the management of spontaneous preterm labor: identification of spontaneous preterm labor, diagnosis of preterm premature rupture of membranes, and preventive tools for preterm birth. J Matern Fetal Neonatal Med. 2011; 24(5): 659-67. doi: 10.3109/14767058.2011.553694.

23. Tian CF, Lv FH, Wang M, Gu XS. Serum betahuman chorionic gonadotropin and interleukin-1 as diagnostic biomarkers for the premature rupture of membranes and chorioamnionitis. Biomed Rep. 2014; 2(6): 905-9. DOI:10.3892/br.2014.342. 
